\title{
2D and 3D QSAR Studies of the Receptor Binding Affinity of Progestins
}

\author{
Lea da Silva Veras, ${ }^{a}$ Masamoto Arakawa, ${ }^{b}$ Kimito Funatsu ${ }^{b}$ and Yuji Takahata ${ }^{*, a, c}$
}

${ }^{a}$ Instituto de Química, Universidade Estadual de Campinas, 6154, 13083-970 Campinas-SP, Brazil

${ }^{b}$ Department of Chemical System Engineering, Faculty of Engineering, The University of Tokyo, 7-3-1, Hongo, Bunkyo-ku, Japan

'Escola de Engenharia, Universidade do Estado do Amazonas, Av. Darcy Vargas, 1200, Parque 10, 69065-020 Manaus-AM, Brazil

Foi realizada uma análise de QSAR-2D com três descritores sobre a afinidade de ligação a receptor no citosolo humano. Um conjunto de vinte e três progesteronas foi dividido em um conjunto de treinamento de dezesseis compostos e em um conjunto de teste de sete compostos. $\mathrm{O}$ método quântico semi-empírico RM1 foi usado para calcular a geometria e algumas propriedades moleculares. O software DRAGON também foi usado para produzir descritores. O software MobyDigs foi usado para selecionar descritores e construir modelos QSAR. O melhor modelo de QSAR foi construído para o conjunto de treinamento usando regressão linear múltipla com três descritores, PW2, Mor15m e GAP-10, resultando em $\mathrm{r}^{2}=0,886, \mathrm{q}^{2}=0,805, \mathrm{q}_{\text {boot }}^{2}=0,723$, e $\mathrm{q}_{\text {ext }}^{2}=0,666$. Um conjunto de nove progesteronas adicionais que não foram usadas para construir $\mathrm{o}$ modelo QSAR foi empregado para validação externa resultando em $\mathrm{q}_{\mathrm{ext}}^{2}=0,403$. A validação também foi feita com funções de aptidão RQK. Foi mostrado que o modelo QSAR satisfaz todos os critérios requeridos para validação, indicando que o modelo de regressão é aceitável. Dois modelos QSAR-3D foram construídos: o primeiro para avaliar o poder preditivo e o segundo para ser analisado. O poder preditivo obtido com o conjunto de nove compostos para avaliação externa foi $\mathrm{q}_{\text {ext }}^{2}=0,476$. Usando a representação gráfica dos coeficientes de regressão de PLS, correspondendo às interações espacial e eletrostática, foi possível obter uma interpretação mecânica. Foi mostrado que QSAR-2D e 3D juntos satisfazem todos os seis requerimentos do Princípio de Setubal (Princípio de OECD). A partir das informações obtidas pelo QSAR-3D foram construídas quatro novas progesteronas. As atividades de afinidade de ligação ao receptor destes novos compostos foram várias vezes maiores que qualquer uma do conjunto de vinte e três progesteronas já estudado.

A 2D QSAR analysis with three descriptors of binding affinity to human cytosol receptor was performed. The set of twenty-three progestins was divided into a training set of sixteen molecules and a test set of seven molecules. The quantum chemical RM1 semiempirical method was used to calculate geometry and some molecular properties. DRAGON software was also use to produce descriptors. MobyDigs software was used to select descriptors and build QSAR models. The best 2D QSAR model was constructed for the training set with multiple linear regression (MLR) using three descriptors, PW2, Mor15m, and GAP-10, resulting in $\mathrm{r}^{2}=0.866, \mathrm{q}^{2}=0.805, \mathrm{q}^{2} \mathrm{boot}=0.723$, $\mathrm{q}_{\text {ext }}^{2}=0.666$. A set of nine additional progestins that were not used for model building was used for external validation resulting $\mathrm{q}_{\text {ext }}^{2}=0.403$. The QSAR model was also validated by RQK fitness functions. It was shown to satisfy all the required criteria for validation. Two 3D QSAR models were built, first, to estimate predictive power, second, to analyze it. The predictive power of the $3 D$ QSAR obtained with the nine external validation compounds was $\mathrm{q}_{\text {ext }}^{2}=0.476$. Based upon the graphical representation of PLS regression coefficients corresponding to steric and electrostatic interactions, it was possible to obtain a mechanistic interpretation. Thus the 2D and 3D QSAR together satisfy all the six Setubal Principles (OECD principles). Based upon the information obtained from the 3D QSAR analysis, the structures of four new progestins are proposed. Their receptor binding activities are estimated to be several times more potent than the most potent progestin of the twenty-three studied.

Keywords: progestins, relative binding affinity, 2D and 3D QSAR

*e-mail: taka@iqm.unicamp.br; yujitakahata@pq.cnpq.br 


\section{Introduction}

Progestins $^{1}$ are sex hormones of which progesterone is the most well known. The two most frequent uses of progestins $^{2}$ are to prevent endometrial hyperplasia from unopposed estrogen in hormone replacement therapy and for hormonal contraception. Progestins are also used to treat endometriosis, dysfunctional uterine bleeding and secondary amenorrhea, and as a palliative treatment of breast cancer, prostate cancer endometrial cancer. Progesterone ${ }^{1}$ is a C-21 steroid hormone involved in the female menstrual cycle, preparing the lining of the uterus for implantation of a fertilized ovum. Continued progesterone secretion is necessary for the completion of pregnancy. Progesterone is used for luteal support in in vitro fertilization (IVF) protocols and for prevention of pre-term birth in pregnant women. ${ }^{3}$ The combined oral contraceptive pill (COCP), often referred to as the birth-control pill, is a combination of an estrogen and a progestin. Progesterone suppresses ovulation. Pregnant women do not conceive again while pregnant. It was this observation that led to the search for synthetic progestins that could be used as oral contraceptives. Progesterone itself requires very large doses to be effective in suppressing ovulation when taken orally because it is degraded in the intestinal tract. ${ }^{1}$ COCP's are currently used by more than 100 million women worldwide and side effects occur in about $6 \%$ of users. ${ }^{4}$ In order to reduce these side effects, studies of other progestins are needed to improve their quality and potency.

The biological activity of progestins is closely related to their binding affinity to the progesterone receptor. In the past, a number of papers were published on the observed receptor binding affinities of progestins to human cytosol receptor proteins. ${ }^{5-11}$ Because of the wide applicability of progestins for human health problems, it is desirable to investigate their receptor binding affinity. Saha et al. ${ }^{12}$ performed a quantitative structure activity relationship (QSAR) analysis of the receptor binding affinity of twenty four progestins (P1-P24) with the electrotopological state atom index (ETSA), ${ }^{13}$ in an attempt to locate the pharmacophore fragment of the molecule. The coefficient of determination $\left(\mathrm{r}^{2}\right)$ of the best QSAR model they obtained was 0.66 , but no cross-validation of the model was reported. Thus, there is the possibility to improve the quality of the QSAR model and investigate new aspects that were not treated in the earlier paper.

The objective of the present work is to search for better QSAR models for a similar set of progestins in the literature and to investigate new aspects that were not treated previously, applying different QSAR techniques from those applied earlier, in order to elucidate the nature of the receptor binding. We also propose the structures of several new progestins that are estimated to be more potent than any one of those involved in the present study. We have applied two dimensional (2D) as well as three dimensional (3D) QSAR techniques to achieve this goal.

According to the Setubal Principles ${ }^{14}$ (currently known as the Organization for Economic Co-operation and Development (OECD) principles ${ }^{15}$ ), a QSAR should, $(i)$ be associated with a defined endpoint; (ii) take the form of an unambiguous and easily applicable algorithm; (iii) ideally, have a mechanistic interpretation; (iv) be accompanied by a definition of domain of applicability; $(v)$ be associated with a measure of goodness-of-fit (internal validation); (vi) be assessed in terms of its predictive power by using data not used in the development of the model (external validation).

In this work we have tried to satisfy all six Setubal Principles. The first principle was satisfied when we stated our objectives. 2D QSAR is suitable to satisfy the majority of the Setubal Principles, while 3D QSAR is suitable for mechanistic interpretation, the $3^{\text {rd }}$ principle. Older studies on steroids and a recent article $^{17}$ relate QSAR studies on progestagens with and without $3 \mathrm{D}$ and are considered in this work.

\section{Methods}

Figure 1 and Table 1 show the set of twenty three progestins (1-23) used to build a QSAR model together with an external set of nine compounds that were used for an external validation, while Table 2 lists their observed log RBA values, where RBA is the relative binding affinity, a measure of biological activity relative to the binding affinity of promegestone( $\mathbf{R 5 0 2 0})$, which is the reference steroid most frequently used in receptor studies. In compiling this list, we found six erroneous $\log$ RBA values ${ }^{18}$ in Table I of Saha et al. ${ }^{12}$ The log RBA values in Table 2 are corrected ones. Table 2 does not include compound $\mathbf{P 0 7}$ of the list of 24 compounds studied by Saha et al. ${ }^{12}$ The log RBA values of compounds P07 and P21 are identical and this causes

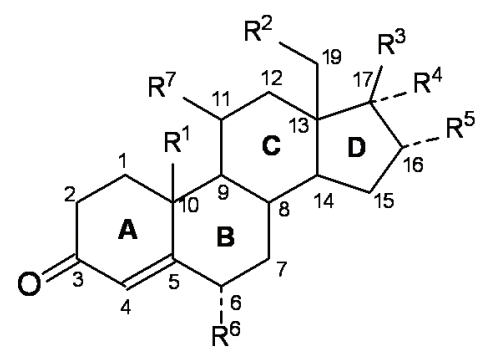

Figure 1. Basic structure of the progestins. $\mathrm{R}^{1}-\mathrm{R}^{7}$ are the substituents listed in Table 1. 
Table 1. The twenty three progestins $(n=23)$ used to build a QSAR model and the nine external validation set (E1-E9) that were never used to build the QSAR model. See Figure 1 for complete structural information

\begin{tabular}{|c|c|c|c|c|c|c|c|c|}
\hline ID & $\mathrm{R}^{1}$ & $\mathrm{R}^{2}$ & $\mathrm{R}^{3}$ & $\mathrm{R}^{4}$ & $\mathrm{R}^{5}$ & $\mathrm{R}^{6}$ & $\mathrm{R}^{7}$ & Note \\
\hline \multicolumn{9}{|c|}{ The 23 Progestins } \\
\hline 1 & $\mathrm{CH}_{3}$ & $\mathrm{H}$ & $\mathrm{COCH}_{3}$ & $\mathrm{H}$ & $\mathrm{H}$ & $\mathrm{H}$ & $\mathrm{H}$ & --- \\
\hline 2 & $\mathrm{CH}_{3}$ & $\mathrm{H}$ & $\mathrm{COCH}_{3}$ & $\mathrm{OCOCH}_{3}$ & $\mathrm{H}$ & $\mathrm{H}$ & $\mathrm{H}$ & --- \\
\hline 3 & $\mathrm{CH}_{3}$ & $\mathrm{H}$ & $\mathrm{COCH}_{3}$ & $\mathrm{OH}$ & $\mathrm{H}$ & $\mathrm{H}$ & $\mathrm{H}$ & --- \\
\hline 4 & $\mathrm{CH}_{3}$ & $\mathrm{H}$ & $\mathrm{COCH}_{2} \mathrm{OH}$ & $\mathrm{H}$ & $\mathrm{H}$ & $\mathrm{H}$ & $\mathrm{H}$ & --- \\
\hline 5 & $\mathrm{CH}_{3}$ & $\mathrm{H}$ & $\mathrm{COCH}_{3}$ & $\mathrm{H}$ & $\mathrm{H}$ & $\mathrm{H}$ & $\mathrm{OH}$ & --- \\
\hline 6 & $\mathrm{CH}_{3}$ & $\mathrm{H}$ & $\mathrm{COCH}_{3}$ & $\mathrm{OCOCH}_{3}$ & $\mathrm{H}$ & $\mathrm{CH}_{3}$ & $\mathrm{H}$ & --- \\
\hline 7 & $\mathrm{CH}_{3}$ & $\mathrm{H}$ & $\mathrm{COCH}_{3}$ & $\mathrm{OCOCH}_{3}$ & $\mathrm{H}$ & $\mathrm{Cl}$ & $\mathrm{H}$ & $\Delta^{6,7}$ \\
\hline 8 & $\mathrm{CH}_{3}$ & $\mathrm{H}$ & $\mathrm{COCH}_{3}$ & $\mathrm{OCOCH}_{3}$ & $\mathrm{H}$ & $\mathrm{Cl}$ & $\mathrm{H}$ & $\begin{array}{l}\Delta^{6,7} \text { and a cyclo-propyl ring } \\
\text { fused at } C 1 \text { and } C 2\end{array}$ \\
\hline 9 & $\mathrm{CH}_{3}$ & $\mathrm{H}$ & $\mathrm{OH}$ & $\mathrm{H}$ & $\mathrm{H}$ & $\mathrm{H}$ & $\mathrm{H}$ & --- \\
\hline 10 & $\mathrm{CH}_{3}$ & $\mathrm{H}$ & $\mathrm{COCH}_{3}$ & $\mathrm{H}$ & $\mathrm{H}$ & $\mathrm{H}$ & $\mathrm{H}$ & Lack $\Delta^{4,5}$ \\
\hline 11 & $\mathrm{CH}_{3}$ & $\mathrm{H}$ & $\mathrm{COCH}_{3}$ & $\mathrm{H}$ & $\mathrm{H}$ & $\mathrm{H}$ & $\mathrm{H}$ & $\Delta^{1,2}$ \\
\hline 12 & $\mathrm{CH}_{3}$ & $\mathrm{H}$ & $\mathrm{COCH}_{3}$ & $\mathrm{H}$ & $\mathrm{H}$ & $\mathrm{H}$ & $\mathrm{H}$ & $\Delta^{6,7}$ \\
\hline 13 & $\mathrm{H}$ & $\mathrm{H}$ & $\mathrm{COCH}_{2} \mathrm{CH}_{3}$ & $\mathrm{CH}_{3}$ & $\mathrm{H}$ & $\mathrm{H}$ & $\mathrm{H}$ & $\Delta^{9,10}$ \\
\hline 14 & $\mathrm{H}$ & $\mathrm{H}$ & $\mathrm{COCH}_{2} \mathrm{OH}$ & $\mathrm{H}$ & $\mathrm{C}_{2} \mathrm{H}_{5}$ & $\mathrm{H}$ & $\mathrm{H}$ & --- \\
\hline 15 & $\mathrm{H}$ & $\mathrm{CH}_{3}$ & $\mathrm{OH}$ & $\mathrm{C} \equiv \mathrm{CH}$ & $\mathrm{H}$ & $\mathrm{H}$ & $\mathrm{H}$ & --- \\
\hline 16 & $\mathrm{H}$ & $\mathrm{H}$ & $\mathrm{COCH}_{3}$ & $\mathrm{H}$ & $\mathrm{H}$ & $\mathrm{H}$ & $\mathrm{H}$ & --- \\
\hline 17 & $\mathrm{H}$ & $\mathrm{H}$ & $\mathrm{OH}$ & $\mathrm{C} \equiv \mathrm{CH}$ & $\mathrm{H}$ & $\mathrm{H}$ & $\mathrm{H}$ & --- \\
\hline 18 & $\mathrm{H}$ & $\mathrm{CH}_{3}$ & $\mathrm{OH}$ & $\mathrm{C} \equiv \mathrm{CH}$ & $\mathrm{H}$ & $\mathrm{H}$ & $=\mathrm{CH}_{2}$ & --- \\
\hline 19 & $\mathrm{H}$ & $\mathrm{CH}_{3}$ & $\mathrm{OH}$ & $\mathrm{C} \equiv \mathrm{CH}$ & $\mathrm{H}$ & $\mathrm{H}$ & $\mathrm{H}$ & $\Delta^{15,16}$ \\
\hline 20 & $\mathrm{H}$ & $\mathrm{H}$ & $\mathrm{OH}$ & $\mathrm{CH}_{2} \mathrm{CH}=\mathrm{CH}_{2}$ & $\mathrm{H}$ & $\mathrm{H}$ & $\mathrm{H}$ & --- \\
\hline 21 & $\mathrm{H}$ & $\mathrm{H}$ & $\mathrm{OH}$ & $\mathrm{C} \equiv \mathrm{CH}$ & $\mathrm{H}$ & $\mathrm{H}$ & $\mathrm{H}$ & $\Delta^{5,10}$ and lack $\Delta^{4,5}$ \\
\hline 22 & $\mathrm{H}$ & $\mathrm{H}$ & $\mathrm{OH}$ & $\mathrm{H}$ & $\mathrm{H}$ & $\mathrm{H}$ & $\mathrm{H}$ & --- \\
\hline 23 & $\mathrm{H}$ & $\mathrm{H}$ & $\mathrm{OH}$ & $\mathrm{CH}_{3}$ & $\mathrm{H}$ & $\mathrm{H}$ & $\mathrm{H}$ & $\Delta^{9,10}$ and $\Delta^{11,12}$ \\
\hline \multicolumn{9}{|c|}{ The 9 External Set } \\
\hline E1 & $\mathrm{CH}_{3}$ & $\mathrm{H}$ & $\mathrm{COCH}_{3}$ & $\mathrm{H}$ & $\mathrm{H}$ & $\mathrm{F}$ & $\mathrm{H}$ & \\
\hline E2 & $\mathrm{CH}_{3}$ & $\mathrm{H}$ & $\mathrm{COCH}_{3}$ & $\mathrm{H}$ & $\mathrm{H}$ & $\mathrm{CH}_{3}$ & $\mathrm{H}$ & \\
\hline $\mathbf{E 3}$ & $\mathrm{CH}_{3}$ & $\mathrm{H}$ & $\mathrm{COCH}_{3}$ & $\mathrm{H}$ & $\mathrm{H}$ & $\mathrm{OH}$ & $\mathrm{H}$ & \\
\hline E4 & $\mathrm{CH}_{3}$ & $\mathrm{H}$ & OAc & $\mathrm{H}$ & $\mathrm{H}$ & $\mathrm{Cl}$ & $\mathrm{H}$ & $\Delta^{6,7}$ \\
\hline E5 & $\mathrm{CH}_{3}$ & $\mathrm{H}$ & OAc & $\mathrm{H}$ & $\mathrm{H}$ & $\mathrm{Cl}$ & $\mathrm{H}$ & $\Delta^{6,7}, 4-\mathrm{Cl}$ \\
\hline E6 & $\mathrm{CH}_{3}$ & $\mathrm{H}$ & $\mathrm{COCH}_{3}$ & $\mathrm{H}$ & $\mathrm{H}$ & $\mathrm{H}$ & $\mathrm{H}$ & $21-\mathrm{Cl}$ \\
\hline E7 & $\mathrm{CH}_{3}$ & $\mathrm{H}$ & $\mathrm{COCH}_{3}$ & $\mathrm{H}$ & $\mathrm{H}$ & $\mathrm{H}$ & $\mathrm{H}$ & $21-\mathrm{OH}$ \\
\hline E8 & $\mathrm{CH}_{3}$ & $\mathrm{H}$ & $\mathrm{COCH}_{3}$ & $\mathrm{H}$ & $\mathrm{H}$ & $\mathrm{CH}_{3}$ & $\mathrm{H}$ & $\Delta^{6,7}$ \\
\hline E9 & $\mathrm{CH}_{3}$ & $\mathrm{H}$ & $\mathrm{COCH}_{3}$ & $\mathrm{H}$ & $\mathrm{H}$ & $\mathrm{H}$ & $\mathrm{H}$ & $\Delta^{16,17}$ \\
\hline
\end{tabular}

calculation problems with some of computer packages that we used, so we removed progestin $\mathbf{P 0 7}$ from the original set of the compounds ${ }^{12}$ for our QSAR analysis. Thus there were a total of 23 progestins in our set that were used to build a QSAR model.

The ground state geometries of the molecules were optimized with the RM1 (Recife Model 1) ${ }^{19}$ semiempirical molecular orbital model found in
HyperChem Professional $8 .^{20}$ The following criteria were used to optimize the ground state geometries: algorithm: Polak-Ribiere; RMS gradient: $0.1 \mathrm{kcal} \mathrm{mol}^{-1}$; maximum number of cycles: 795; solvent: in vacuo. The RM1 method is essentially identical to the AM1 method, but with improved performance and with newer and better parameters. In most cases, RM1 yields results superior to both AM1 and PM3. The RM1 semiempirical quantum 
Table 2. Observed and calculated $\log$ RBA and values of the three selected descriptors, PW2, Mor $15 \mathrm{~m}$ and GAP-10 for the 23 progestins

\begin{tabular}{|c|c|c|c|c|c|c|c|}
\hline $\mathrm{ID}^{* *}$ & name & Ref. & $\begin{array}{l}\log \mathrm{RBA}^{*} \\
\text { Obs. }\end{array}$ & $\begin{array}{l}\log \text { RBA } \\
\text { Calc. }\end{array}$ & PW2 & Mor15m & GAP- $10 / \mathrm{eV}$ \\
\hline $\mathbf{1}^{\#}$ & Progesterone & 5 & 1.602 & 1.194 & 0.620 & 0.198 & 0.094 \\
\hline 2 & 17-Acetoxyprogesterone & 6 & 1.204 & 1.236 & 0.620 & 0.401 & 0.139 \\
\hline 3 & 17-Hydroxyprogesterone & 6 & 0.079 & 0.094 & 0.631 & 0.535 & 0.256 \\
\hline $4^{\#}$ & 21-Hydroxyprogesterone & 6 & 1.049 & 0.954 & 0.612 & 0.424 & 0.246 \\
\hline 5 & $11 \beta$-Hydroxyprogesterone & 6 & 1.158 & 1.432 & 0.621 & 0.252 & 0.066 \\
\hline 6 & Methoxyprogesterone acetate & 5 & 2.061 & 1.418 & 0.622 & 0.389 & 0.095 \\
\hline 7 & Chloromadinone acetate & 7 & $1.975^{\mathrm{a}}$ & 2.330 & 0.622 & 0.720 & 0.046 \\
\hline 8 & Cyproterone acetate & 7 & $1.447^{\mathrm{b}}$ & 1.228 & 0.629 & 0.852 & 0.187 \\
\hline 9 & Testosterone & 6,8 & -0.097 & -0.009 & 0.624 & 0.227 & 0.246 \\
\hline $10^{\#}$ & $5 \beta$-Pregnane-3,20-dione & 6 & 0.380 & 1.092 & 0.620 & -0.046 & 0.048 \\
\hline 11 & 1,4-Pregnadine-3,20-dione & 6 & 1.318 & 1.502 & 0.620 & 0.341 & 0.086 \\
\hline $12^{\#}$ & 4,6-Pregnadine-3,20-dione & 6 & 1.310 & 1.218 & 0.620 & 0.441 & 0.152 \\
\hline 13 & Promegestone (R5020) & 5 & 2.000 & 2.075 & 0.604 & 0.673 & 0.206 \\
\hline 14 & $\begin{array}{l}\text { 16 } \alpha \text {-Ethyl-21-hydroxy-19-nor-4-pregnene-3,20-dione } \\
\text { (Organon 2058) }\end{array}$ & 5,9 & 2.544 & 2.557 & 0.597 & 0.454 & 0.133 \\
\hline $15^{\#}$ & Levonorgestrel & 5 & 2.079 & 2.474 & 0.605 & 0.295 & 0.046 \\
\hline 16 & 19-Norprogesterone & 6,8 & 1.827 & 1.794 & 0.610 & 0.342 & 0.118 \\
\hline 17 & Norethisterone & 10 & 1.866 & 1.542 & 0.615 & 0.267 & 0.099 \\
\hline 18 & 3-Keto-desogestrel & 10 & 2.827 & 2.534 & 0.607 & 0.523 & 0.079 \\
\hline $19^{\#}$ & Gestodene & 10 & 2.799 & 2.249 & 0.605 & 0.277 & 0.074 \\
\hline $20^{\#}$ & 3-Keto-allylestrenol & 7,9 & $1.886^{\mathrm{c}}$ & 2.188 & 0.606 & 0.199 & 0.055 \\
\hline 21 & Norethinodrel & 7 & $0.845^{\mathrm{d}}$ & 1.476 & 0.615 & 0.445 & 0.153 \\
\hline 22 & 19-Nortestosterone & 6,8 & 0.944 & 0.827 & 0.613 & 0.369 & 0.243 \\
\hline 23 & Metribolone (R1881) & 7 & $2.146^{\mathrm{e}}$ & 2.111 & 0.625 & 0.945 & 0.112 \\
\hline
\end{tabular}

*Confidence limits: ${ }^{\mathrm{a}}(1.906-2.035) ;{ }^{\mathrm{b}}(1.322-1.544) ;{ }^{\mathrm{c}}(1.775-1.975) ;{ }^{\mathrm{d}}(0.544-1.021) ;{ }^{\mathrm{e}}(2.021$ - 2.276$) ;{ }^{*}$ The seven test set molecules; $* *$ The remaining 16 molecules belong to the training set.

mechanical calculation produces physical properties related to the electronic structure of the molecule.

Molecular orbital energies and Mulliken atomic charges calculated by RM1 were employed as QSAR descriptors. The $\mathrm{K}^{\text {th }}$ level below the highest occupied molecular orbital (HOMO) and its energy is represented as HOMO-K, where $\mathrm{K}=0,1,2, . ., 30$. Likewise, the $\mathrm{L}^{\mathrm{th}}$ level above the lowest unoccupied molecular orbital (LUMO) and its energy is represented as LUMO+L, where L $=0,1,2, \ldots, 10$. Energy separations between two adjacent molecular orbitals are calculated and denominated as "GAP". For instance, GAP-10 is defined as the energy separation between the HOMO- $9^{\text {th }}$ orbital and the HOMO- $10^{\text {th }}$ orbital. The total number of GAP-M calculated was 28 , i.e. $\mathrm{M}=1,2, \ldots, 28$. Atomic charges on the seventeen carbon atoms of the steroid skeleton, heats of formation, electronic energies, and others were also used as descriptors. A total of 105 quantum mechanical descriptors for each molecule were generated. The software DRAGON ${ }^{21}$ was used to calculate other types of descriptors. All the twenty descriptor blocks available in the package ranging from $0 \mathrm{D}$ to $3 \mathrm{D}$ descriptors in the program were selected for descriptor calculations. A total of 1664 molecular descriptors were calculated. The descriptors that had intercorrelation values greater than 0.9 were eliminated. This reduced the number of molecular descriptors to 245. Adding the 105 quantum mechanical descriptors and the 245 DRAGON-derived descriptors resulted in a total of 350 descriptors for each molecule. The software MobyDigs ${ }^{22}$ was used for descriptor selection and QSAR model building.

The set of the 23 progestins in Table 1 were divided into a training set and a test set. The training set consisted of 16 progestins, whereas the test set consisted of 7 progestins $(1,4,10,12,15,19,20)$, chosen based on an even distribution of the biological activity in these molecules. A three descriptor QSAR model was searched using a genetic algorithm (GA) ${ }^{23}$ In the genetic algorithm window, default values were used. A cross-validated correlation 
coefficient, $\mathrm{q}^{2}$, was selected as the fitness function. As the criteria for descriptor selection, we choose descriptors that give the highest value of $\mathrm{q}_{\mathrm{ext}}{ }^{2}$, an external ${ }^{24} \mathrm{q}^{2}$, for the seven compounds of the test set. This means that we searched for descriptors that result in a QSAR model that has the greatest predictive ability. In order to estimate true predictive power of the QSAR model, we compare the predicted and observed activities of the nine compounds of the external validation set (Tables 1 and 3 ) that were not used in the model development. The second Setubal Principle was satisfied in this section.

\section{Results and Discussion}

Equation 1 is the best QSAR model obtained with three descriptors:

$\log \mathrm{RBA}=-51.65( \pm 20.77) \mathrm{PW} 2+1.740( \pm 0.8910)$ Mor15m $6.915( \pm 2.797)(\mathrm{GAP}-10)+33.52( \pm 12.69)$

where $\left(n=16 ; r^{2}=0.866 ; s=0.331 ; F=25.94 ; p<0.0001\right.$; $\mathrm{q}^{2}=0.805 ; \mathrm{q}_{\text {boot }}^{2}=0.723, \operatorname{SDEP}=0.346 ; \operatorname{SDEC}=0.287 ;$ $\mathrm{Kxx}=11.91 ; \mathrm{Kxy}=37.56 ; \Delta \mathrm{K}=25.65$ ).

PW2 is the Randic path/walk shape index. ${ }^{25}$ It is among the topological descriptors and demonstrates that the quotient $\left(\mathrm{P}_{\mathrm{i}} / \mathrm{W}_{\mathrm{i}}\right)$ of $\mathrm{i}$-th path length $\left(\mathrm{P}_{\mathrm{i}}\right)$ and walk length $\left(\mathrm{W}_{\mathrm{i}}\right)$ of a molecule in graph theory can correlate many physicochemical properties of the molecule, such as density, critical pressure, molar refraction, heat of formation, steric interactions, entropy, and others. PW2 is defined as $\left(\mathrm{P}_{2} / \mathrm{W}_{2}\right)$, the quotient of path length of $2\left(\mathrm{P}_{2}\right)$ and walk length of $2\left(\mathrm{~W}_{2}\right)$. Since PW2 is expected to correlate many physicochemical properties of the progestins, PW2 should also correlate with its biological activity.

Mor $15 \mathrm{~m}$ is the 3D-MORSE (molecule representation of structures based on electron diffraction) code of signal 15 , weighted with atomic masses. Methods such as X-ray and electron diffraction yield diffraction patterns from which the atomic coordinates are derived by mathematical transformations. Inversely, three-dimensional atomic coordinates can be transformed into a code by an equation similar to the one used in electron diffraction for preparing scattering carves. The intensity of scattered radiation, I(s), can be approximated by equation 2 :

$$
\begin{aligned}
& I(s)=\sum_{i=2}^{N} \sum_{j=1}^{i-1} A i A j \frac{\sin \left(s r_{i j}\right)}{s r_{i j}} \\
& \mathrm{~s}=0, \ldots, 31.0 \AA^{-1}
\end{aligned}
$$

where s measures the scattering angle, $r_{i j}$ represents the distance between the $i^{\text {th }}$ and the $j^{\text {th }}$ atoms, $A_{i}$ represents the atomic properties of the $\mathrm{i}^{\text {th }}$ atom, such as atomic mass, partial atomic charge, and others, and $\mathrm{N}$ is the number of atoms in the molecule. Values of equation 2 were calculated at 32 evenly distributed values of $s$ in the range of $0-31 \AA^{-1}$ from the three-dimensional atomic coordinates of a molecule. These 32 values constitute the 3D-MORSE code of the three-dimensional structure of a molecule. The 3D-MORSE code allows the representation of the threedimensional structure of a molecule by a fixed number of values.

As indicated earlier, GAP-10 is the energy separation between the HOMO- $9^{\text {th }}$ orbital and the HOMO- $10^{\text {th }}$ orbital. It conveys information concerning electronic structure of a molecule. But why GAP-10 is correlated with $\log$ RBA is not known.

The statistical parameters for equation 1 are: standard deviation error of prediction (SDEP), standard deviation error in calculation (SDEC), while $\mathrm{Kxx}$ is the total correlation in the model predictors (x) and Kxy is the total correlation in the set given by the model predictors $\mathrm{X}$ plus the response $\mathrm{Y} . \Delta \mathrm{K}$ is the difference between $\mathrm{Kxy}$ and $\mathrm{Kxx}$. Correlation coefficients, in parentheses, between two out of the three descriptors are PW2/Mor15m (0.219); PW2/GAP-10 (0.213); Mor15m/GAP-10 (0.275). The correlation coefficients are all less than 0.3. Correlation coefficients $(\mathrm{r}$ ) between the Y-value and an individual descriptor that appears in equation 1 are -0.60 (PW2), -0.54 (GAP-10) and +0.27 (Mor $15 \mathrm{~m}$ ) respectively. The degree of contribution of the two descriptors, PW2 and GAP-10, to the QSAR model is about the same. They are the most significant. PW2 and Mor 15m are descriptors that are related to topology and 3D molecular geometry, while GAP-10 is related to electronic structure of the molecule. Since the correlation between PW2 and the Y-values is negative, the smaller the value of PW2 of a compound, the greater its biological activity. The same statement also applies to GAP-10 since it has negative correlations with the Y-values. In order to define the applicability domain (AD) of the QSAR model (4 ${ }^{\text {th }}$ Setubal Principle), a Williams Plot (Figure 2) is presented. This plot contains both the training (open squares) and the test set (filled squares) compounds. All the compounds except one lie within the limit of $\mathrm{AD}$. One test compound is outside the $3 \sigma$ line, although it is close to the line and has been retained. Internal validation $\left(5^{\text {th }}\right.$ Setubal Principle) resulted in one or more measures of robustness of the model parameters such as $\mathrm{q}^{2}(0.805)$, $\mathrm{Y}$-scrambling $\left(\mathrm{a}\left(\mathrm{r}^{2}\right)=0.111\right.$, $\left.\mathrm{b}\left(\mathrm{q}^{2}\right)=-0.634\right)$ and internal predictability such as $\mathrm{q}_{\text {bootstrap }}^{2}$ (0.77) (equation 1). There are no chance correlations because of the low Y-scrambling parameter values, since they satisfy the criteria $\mathrm{a}\left(\mathrm{r}^{2}\right)<0.3$ and $\mathrm{b}\left(\mathrm{q}^{2}\right)<0.05$. The 
co-linearity of the descriptors, the block of $\mathrm{X}$ variables, is low $(\mathrm{Kx}=0.12)$. The difference in the correlation between the block of $\mathrm{X}$ variables plus the response $\mathrm{Y}(\mathrm{Kxy})$ and that of $\mathrm{X}(\mathrm{Kxx})$ is sufficiently high $(\mathrm{DK}=0.256)$. The value of $\mathrm{q}_{\text {bootstrap }}^{2}$ is fairly close to $\mathrm{q}^{2}$ confirming the internal predictability and stability of the model. The difference between $\mathrm{r}^{2}$ and $\mathrm{q}^{2}$ is not large. In view of these observations, we conclude that the QSAR model of equation 1 is fairly robust.

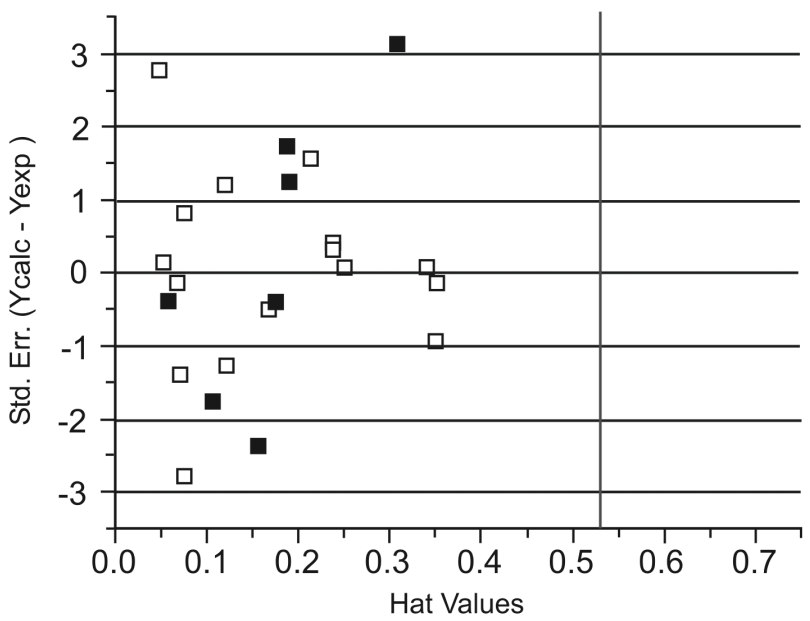

Figure 2. Williams plot. The plot contains both the training set (open squares) and the test set (filled squares) compounds.

External validation ( $6^{\text {th }}$ Setubal Principle) refers to a validation exercise in which the chemical structures selected for inclusion in the validation (or test) set are different from those included in the training set. Our seven test set compounds among the original 23 molecules belong to the same chemical domain, as seen in the Williams plot (Figure 2). External validation for the set is accessed by $\mathrm{q}_{\text {ext }}^{2}$. The value of $\mathrm{q}_{\text {ext }}^{2}$ is 0.67 , which is smaller than $\mathrm{q}^{2}$, but not too much different. Thus the value of 0.67 for $\mathrm{q}_{\text {ext }}^{2}$ is acceptable. The seven test set compounds for the external validation were used to select the best QSAR model, equation 1 .

In order to asses true predictive power of the QSAR model (equation 1), we calculated log RBA values of the nine compounds of the external validation set that were not used in the model development. The predicted values are listed in the column designated as "Predict (2D)" in Table 3. The value of $\mathrm{q}_{\text {ext }}^{2}$ for the validation set was 0.403 (Table 3) which is lower than 0.67 that was obtained with the test set of the seven molecules.

The leave-one-out variance $\mathrm{q}^{2}$ has sometimes been demonstrated to be too optimistic in evaluating prediction ability of regression models. Todeschini et al. ${ }^{26}$ proposed a set of more severe validation criteria than $\mathrm{q}^{2}$ using $\mathrm{RQK}$ fitness functions (Table 4).

Comparison of the last two columns of Table 4 reveals that our QSAR model (equation 1) satisfies all five of the Todeschini criteria. Figure 3 shows a plot of the calculated $\log$ RBA against the observed values.

The nature of the three selected descriptors, PW2, GAP-10 and Mor15m, does not permit one to draw a clear mechanistic interpretation ( $3^{\text {rd }}$ Setubal Principle). However, the 3D QSAR method is expected to provide a mechanistic interpretation. Physicochemical interpretation of a 3D QSAR model is straightforward as only two kinds of descriptors, steric and electrostatic interactions, are employed. 3D QSAR was performed using the software ToMoCo, ${ }^{27}$ which employs a grid approach. ${ }^{28}$ The grid approach attempts to establish a relationship between the biological activities and the steric/electrostatic properties between a set of compounds. A superposition rule for these compounds is defined. The steric and electrostatic

Table 3. Observed and two set of predicted log RBA's, first by equation 1 (2D QSAR), and second, by the 3D QSAR, and values of the three selected descriptors, PW2, Mor15m and GAP-10 for the external set of the nine progesntins (E1-E9)

\begin{tabular}{|c|c|c|c|c|c|c|c|c|}
\hline \multirow[t]{2}{*}{ ID } & \multirow[t]{2}{*}{ name } & \multirow[t]{2}{*}{ Ref. } & \multicolumn{3}{|c|}{$\log \mathrm{RBA}$} & \multirow[t]{2}{*}{ PW2 } & \multirow[t]{2}{*}{ Mor15m } & \multirow[t]{2}{*}{ GAP-10/eV } \\
\hline & & & Obs. & Predict (2D) & Predict (3D) & & & \\
\hline $\mathbf{E 1}$ & $6 \alpha$-Fluoro-4-pregnene-3,20-dione & 8 & 1.566 & 1.083 & 0.442 & 0.622 & 0.317 & 0.125 \\
\hline $\mathbf{E 2}$ & $6 \alpha$-Methyl-4-pregnene-3,20-dione & 8 & 1.017 & 0.622 & 0.889 & 0.622 & 0.202 & 0.163 \\
\hline $\mathbf{E 3}$ & 4-Pregnen-6 $\beta$-ol-3,20-dione & 8 & -0.097 & 0.293 & 0.376 & 0.622 & 0.122 & 0.190 \\
\hline $\mathbf{E 4}$ & 6-Chloro-4,6-pregnadiene-17 $\alpha$-ol-3,20-diene & 8 & 1.301 & 1.534 & 1.096 & 0.622 & 0.723 & 0.162 \\
\hline E5 & $\begin{array}{l}\text { 4,6-Dichloro-4,6-pregnadiene-17 } \beta \text {-ol-3,20-dione } \\
\text { acetate }\end{array}$ & 8 & 0.903 & 1.517 & 1.515 & 0.625 & 0.886 & 0.183 \\
\hline E6 & 21-Chloro-4-pregnene-3,20-dione & 8 & 0.556 & 1.486 & 0.477 & 0.612 & 0.4 & 0.163 \\
\hline E7 & 4-Pregnene-21-ol-3,20-dione & 8 & 1.049 & 1.956 & 0.366 & 0.612 & 0.311 & 0.072 \\
\hline E8 & 6-Methyl-4,6-pregnadiene-3,20-dione & 8 & 1.193 & 0.921 & 1.461 & 0.622 & 0.453 & 0.183 \\
\hline \multirow[t]{2}{*}{ E9 } & 4,16-Pregnadiene-3,20-dione & 8 & -0.097 & 0.763 & 0.669 & 0.62 & 0.376 & 0.201 \\
\hline & $\mathrm{q}_{\mathrm{ext}}^{2}$ & & & 0.403 & 0.476 & & & \\
\hline
\end{tabular}


Table 4. RQK fitness functions, their thresholds, as suggested by Todeschini et al. ${ }^{26}$ as criterion for validation of a QSAR model, and their corresponding values obtained from the QSAR model shown in equation 1

\begin{tabular}{llll}
\hline Item & RQK fitness functions & Suggested threshhold & Parameter values produced by QSAR model, equation 1 \\
\hline 1 & $\mathrm{q}^{0}:$ & $\mathrm{q}^{2}>0.5$ & $\mathrm{q}^{2}=0.805$ \\
2 & QUIK rule & $\mathrm{DK}=\mathrm{K}_{\mathrm{XY}}-\mathrm{K}_{\mathrm{X}}>0.03$ & $\mathrm{DK}=0.256$ \\
3 & Asymptotic $\mathrm{q}^{2}$ rule & $\mathrm{DQ}=\mathrm{q}_{\text {LOO }}^{2}-\mathrm{q}_{\text {ASYM }}^{2}>0$ & $\mathrm{DQ}=0.043$ \\
4 & $\mathrm{R}^{\mathrm{P}}$ rule & $\mathrm{R}^{\mathrm{P}}>0.05$ & $\mathrm{R}^{\mathrm{P}}=0.248$ \\
5 & $\mathrm{R}^{\mathrm{N}}$ rule & $\mathrm{R}^{\mathrm{N}}>-0.31$ & $\mathrm{R}^{\mathrm{N}}=0$ \\
\hline
\end{tabular}

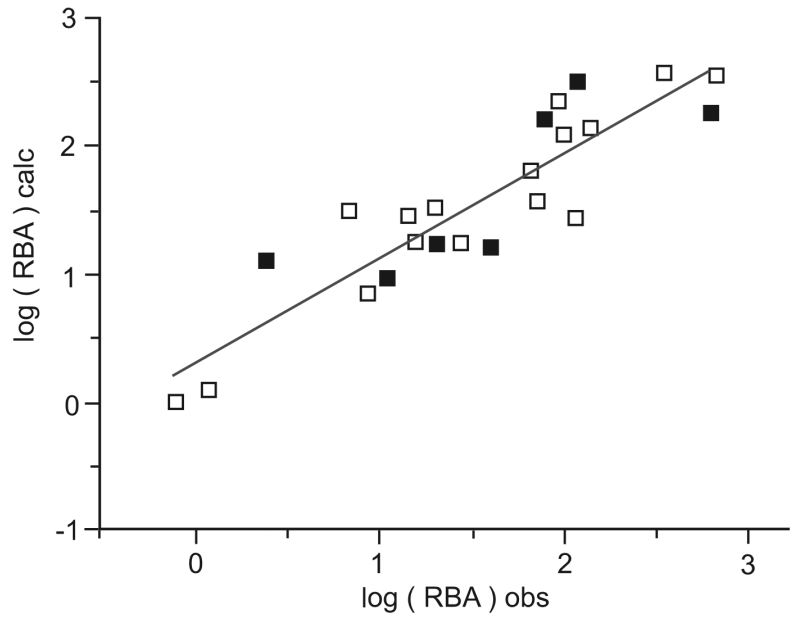

Figure 3. Graph of calculated log RBA against observed values. The graph contains both the training set (open squares) and the test set (filled squares) compounds.

interaction energies with a probe atom of each compound are calculated at each grid point in the grid box spanning 3D space. Atomic charges were calculated with the PM3 method as is required with ToMoCo. They were used for calculation of electrostatic field values. Carbon atoms with $\mathrm{sp}^{3}$ configurations and +1 charge were used as probes. 3D QSAR was performed twice, first to evaluate predictive power of the 3D QSAR, second to produce 3D grid field for analysis and ligand construction. In the first 3D QSAR modeling, exactly the same training set of the sixteen compounds (Table 2) as the one used previously for 2D QSAR modeling was employed. Four carbons, C1 to $\mathrm{C} 4$, were used to superimpose the set of molecules. The average RMS error of the superposition was $0.0514 \AA$. The lattice interval of the grid box was chosen to be $1.0 \AA$. There were 4256 lattice points in the box. VDW and electrostatic field values were calculated with this box. A 3D QSAR model was constructed using PLS with eleven components. The resulting values of $\mathrm{r}^{2}$ and $\mathrm{q}^{2}$ were 1.000 and 0.959 , respectively. The 3D QSAR model was used to predict log RBA's of the nine external validation compounds and listed in Table 3 in the column marked as "Predict (3D)". The value of $\mathrm{q}_{\mathrm{ext}}{ }^{2}$ obtained is 0.476 which can be compared with the corresponding value of 0.403 obtained with 2D QSAR, equation 1. The 3D QSAR model has slightly better predictive power than $2 \mathrm{D}$ QSAR for the type of compounds and the type of biological activity that we are dealing. In the second 3D QSAR modeling, the whole set of the 23 geometry optimized molecules with the Y-values (biological activities), Tables 1 and 2, were entered into ToMoCo. The lattice interval of the grid box was chosen to be $1.0 \AA$. There were 6048 lattice points in the box. A 3D QSAR model was constructed using PLS with seven components from which $q^{2}$ took its maximum value. The resulting values of $\mathrm{r}^{2}$ and $\mathrm{q}^{2}$ were 0.962 and 0.678 , respectively. The model gave Figure 4, which shows a graphical representation in cube format for the grid points associated to the larger regression coefficients of the PLS model.

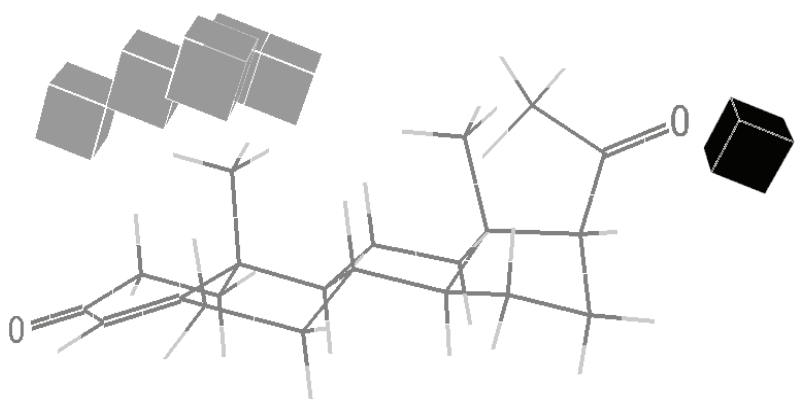

Figure 4. A graphical representation in cube format for the grid points associated with the larger regression coefficients of the PLS model obtained for steric interactions, with positive effects in black and negative ones in gray.

There are some gray cubes closely packed on the $\beta$-side of the A-ring of the steroid skeleton. A gray cube corresponds to a negative regression coefficient. It implies that if there is an atom or a group of atoms in the region where the gray cubes are located, the Y-value (binding affinity) of the molecule will decrease. Williams and Sigler ${ }^{29}$ published an atomic structure of progesterone complexed with its receptor. Their Figures $2 a$ and $2 b$ show that it is the A-ring side of progesterone that establishes a close contact with the progesterone-binding pocket. If a progestin has a (large) substituent that occupies $\beta$-side of A-ring, it will block its entrance to the binding pocket and 
its binding affinity will decrease. On the other hand, if a progestin has no substituent on the $\beta$-side of the A-ring, this will permit its entrance into the binding pocket and binding affinity will increase. This is what we observe in majority of progestins (compounds 13-23 in Tables 1 and 2) that have no $\beta-\mathrm{CH}_{3}$ at $\mathrm{C}_{10}$ in the A-ring.

There is a black cube located outside of $\mathrm{C}_{17}$ of the D-ring of the steroid. A black cube corresponds to a positive regression coefficient. If there is a bulky substituent in the region where the black cube is located, the Y-value will increase. Figure 2a of Williams and Sigler ${ }^{27}$ shows the existence of open space in external region of the D-ring. If there were bulky substituents at $\mathrm{C}_{17}$ of the D-ring stretching towards the empty space, it would help stabilize the steroid, contributing to an increase of binding affinity (see progestins 6,7,20).

Figure 5 shows a graphical representation in cube format for the grid points associated with the larger regression coefficients of the PLS model obtained for electrostatic interaction. There is a black cube on $\beta-\mathrm{CH}_{3}$ at $\mathrm{C}_{10}$ in A-ring. The black cube corresponds to a positive regression coefficient. If there are positive substituents in the region where the black cube is located, the Y-value (binding affinity) of the molecule will increase. Substitution of the $\beta-\mathrm{CH}_{3}$ at $\mathrm{C}_{10}$ with $\beta$-H usually increases the $\mathrm{Y}$-value, as is the case of progestins $13,14,15 \ldots 18$, 19, 20.

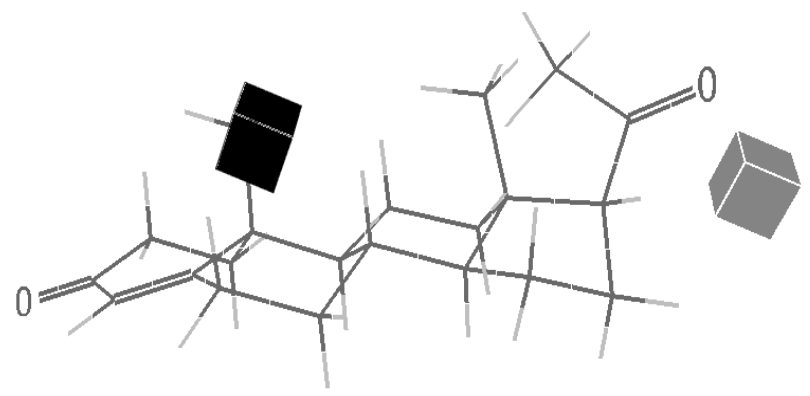

Figure 5. A graphical representation in cube format for the grid points associated with the larger regression coefficients of the PLS model obtained for electrostatic interactions, with positive effects in black and negative ones in gray.

There is a gray cube on the $\alpha$-side of $\mathrm{C}_{17}$ in the D-ring. A gray cube represents a negative sign. If there is negative substituents in the region where the gray cube is located, the Y-value (binding affinity) of the molecule will increase. Some progestins have ethynyl $(\mathrm{C} \equiv \mathrm{CH})$ at $\alpha-\mathrm{C}_{17}$. Ethynyl is an electron rich radical that can be considered a negative substituents. Progestins 15, 18, and 19 have ethynyls at $\alpha-\mathrm{C}_{17}$ and they have high Y-values. Thus the 3D QSAR has helped to provide a mechanistic interpretation (third Setubal Princple).
The analyses of Figures 4 and 5 suggest that new progestins should be modeled by substituting some of hydrogen atoms in the D-ring of the molecule with appropriate substituents. ToMoCo has a package called "LigConstructor" with which one can model new chemical structures. Gestodene (19) was selected as a "seed", because it is one of the most potent progestins and a typical one. A seed molecule is a starting molecule from which a new molecule is modeled, with the aim of designing potential progestins that could be more potent than gestodene. The field that gave Figures 4 and 5, plus the seed molecule, were used as input for LigConstructor. Figure 6 shows the four progestins, (A)-(D), that were modeled.

The estimated $\log$ RBA activity values of the four are: (A) 3.703; (B) 3.520; (C) 3.440; (D) 3.373. The log RBA value of gestodene is 2.799 . The most potent progestin in Table 2 is 3-keto-desogestrel (18) that has a log RBA value of 2.827 . The activities of the four newly modeled progestins are all greater than 3-keto-desogestrel (18), the most potent in Table 2. If progesterone (1) is taken as a reference molecule, 3-keto-desogestrel (18) is 17 times more potent than progesterone (1), the newly modeled progestins (A-D) are estimated to have potencies, 126 times (A), 83 times (B), 69 times $(\mathbf{C})$ and 59 times (D) greater than progesterone (1). A would be 8 times more potent than 18, the most potent in Table 2. There is no guarantee that the newly modeled progestins, (A)-(D), really would have the estimated activity values. Equation 1 (the 2D-QSAR model) was invoked to predict log RBA values of the four new compounds. The predicted values are; (A) 3.586 (3.703), (B) 3.898(3.502), (C) 3.466(3.440), (D) 2.669 (3.373). The value in parenthesis is log RBA value predicted by the $3 \mathrm{D}-\mathrm{QSAR}$ model. The $2 \mathrm{D}$ and $3 \mathrm{D}$ QSAR models predicted almost the same activity values for the compound $(\mathbf{C})$. The two QSAR models predicted improved values for (A) and (B). For compound (D), the two models predicted somewhat different activity values. Both the 2D and 3D QSAR models predicted improved $\log$ RBA values for $(\mathbf{A})-(\mathbf{C})$. This might be an indication that the three compounds, (A)-(C), would have higher activity than any one of Tables 2 and 3 . The only way to verify this would be to synthesize them and measure their activity in the laboratory. However, these experiments are beyond the scope of the present work. If the modeled progestins were proven to really show the high potencies estimated, they could be used in hormone replacement therapy and for hormonal contraception. The combined oral contraceptive pill uses some of progestins shown in Table 2 and they could be substituted by one of the proposed potent progestins. 


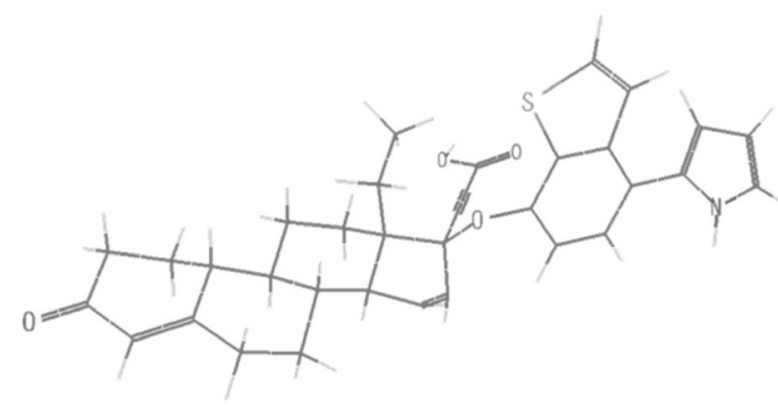

(A) Estimated $\log \mathrm{RBA}=3.703$

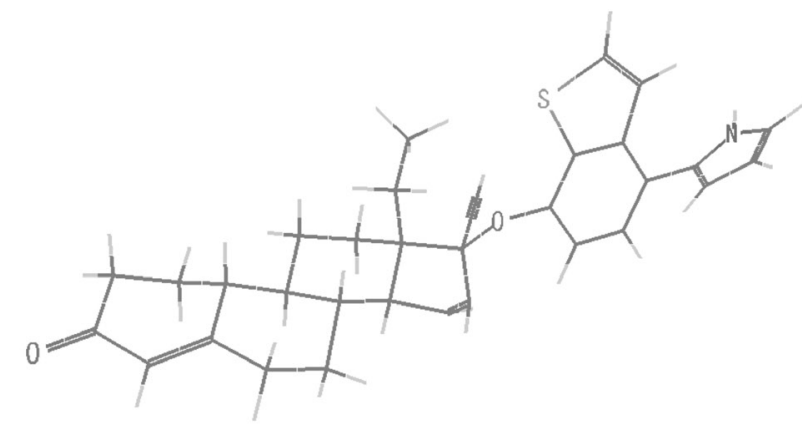

(C) Estimated $\log \mathrm{RBA}=3.440$

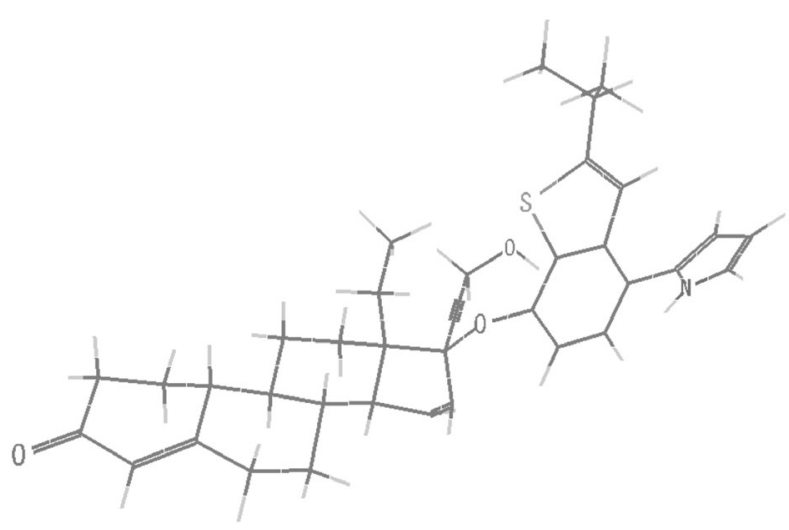

(B) Estimated $\log \mathrm{RBA}=3.502$

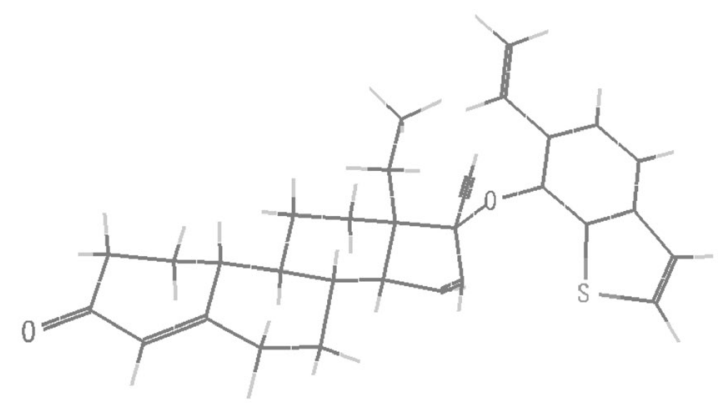

(D) Estimated $\log \mathrm{RBA}=3.373$

Figure 6. Four proposed progestins, (A) - (D), whose receptor binding affinity activities (log RBA) are greater than 3-keto-desgestrel, the most potent progestin in Table 2. The six-member ring in the substituent at $\mathrm{C} 17 \alpha$ is phenyl ring.

\section{Conclusions}

2D QSAR analysis of the binding affinity of a set of 23 progestins to human cytosol receptor proteins was performed. It was shown that the QSAR model satisfies five out of the six Setubal (OECD) Principles. The only principle that the 2D QSAR model does not satisfy is mechanistic interpretation, which was carried out using a 3D QSAR methodology, resulting in graphical representations in cube format for the grid points associated with the larger regression coefficients of the PLS model obtained for steric and electrostatic interactions. Thus, it was demonstrated that a combination of $2 \mathrm{D}$ and $3 \mathrm{D}$ analysis enables one to satisfy all the six Setubal Principles. Based upon the information obtained from the 3D QSAR analysis, four new progestins were constructed, whose receptor binding activities are estimated to be several times more potent than the most potent progestin listed in Table 2 .

\section{Acknowledgments}

The authors thank professors Carol H. Collins and Fred Y. Fujiwara of Universidade Estadual de Campinas Unicamp for english revision and professors Alberto dos
S. Marques and José Luis de Souza Pio of Universidade do Estado do Amazonas, Rogerio Custodio and Marcia M. C. Ferreira of UNICAMP for constructive comments. We acknowledge the Conselho Nacional de Desenvolvimento Científico e Tecnológico (CNPq) and the Fundação de Amparo à Pesquisa do Estado de São Paulo (FAPESP) for financial support.

\section{References}

1. Solomons, T. W. G.; Fryhle, C. B.; Organic Chemistry, $8^{\text {th }}$ ed., John Wiley \& Sons,. Inc.: New York, 2004. ISBN: 978-0-47141799-6

2. http://en.wikipedia.org/wiki/Progestin, accessed in February 2009.

3. Loose, D. S.; Stancel, G. M. In Goodman \& Gilman's The Pharmacological Basis of Therapeutics, $11^{\text {th }}$ ed.; Brunton, L. L.; Lazo, J. S.; Parker, K. L., eds.; McGraw-Hill: New York, 2004, pp. 1541-71. ISBN 0-07-142280-3.

4. Fortherby, K.; Caldwell, A. D. S.; Contraception 1994, 49, 1.

5. Juchem, M.; Pollow, K.; Am. J. Obstet. Gynecol. 1990, 163, 2171.

6. Blanford, A. T.; Wittman, W.; Stroupe, S. D.; Westphal, U.; J. Steroid Biochem. Mol. Biol. 1978, 9, 187. 
7. Bergink, E. W.; Meel, F. V.; Turpijin, E. W.; Vies, J. V.; J. Steroid Biochem. Mol. Biol. 1983, 19, 1563.

8. Smith, H. E.; Smith, R. G.; Toft, D. O.; Neegaard, J. R.; Burrowa, E. P.; O'Malley, B. W.; J. Biol. Chem. 1974, 249, 5294.

9. Bergink, E. W.; Loonen, P. B. A.; Kloosterboer, H. J.; J. Steroid Biochem. Mol. Biol. 1985, 23, 165.

10. Kloosterboer, H. J.; Vonk-Noordegraaf, C. F; Turpijin, E. W.; Contraception 1988, 38, 325.

11. McRobb, L.; Handelsman, D. J.; Kazlauskas, R.; Wilkinson, S.; McLeod, M. D.; Heather, A. K.; J. Steroid Biochem. Mol. Biol. 2008, 110, 39.

12. Saha, A.; Roy, K.; De, K.; Sengupta, C.; Indian J. Chem. 2002, $41 B, 1268$.

13. Kier, L. B.; Hall, L. H.; Pharm. Res. 1990, 7, 801.

14. Gramatica, P.; QSAR Comb. Sci. 2007, 26, 694.

15. http://ecb.jrc.ec.europa.eu/qsar/background/index. php?c=OECD, accessed on July 2009.

16. Coburn, R. A.; Solo, A. J.; J. Med. Chem. 1976, 19, 748; SchulteHermann, R.; Ochs, H.; Bursch, W.; Parzefall, W.; Cancer Res. $1988,48,2462$.

17. Bursi, R.; Groen, M. B.; Eur. J. Med. Chem. 2000, 35, 787.

18. $\log$ RBA values: (ID) correct (wrong): (10) 0.380 (0.778); (11) 1.318 (1.716); (12) 1.310(1.708); (17) 1.866 (1.426); (18) 2.827 (1.426); (19) 2.799 (2.493).
19. Rocha, G. B.; Freire, R. O.; Simas, A. M.; Stewart. J. J. P.; J. Comput. Chem. 2006, 27, 1101.

20. Hypercube, Inc., $1115 \mathrm{NW} 4^{\text {th }}$ st., Gainesville, FL, 32608, USA.

21. DRAGON for Windows and Linux 2006, Talete Srl, Milano, Italy.

22. MobyDigs, Version 1-2004, Talete srl, Milano, Italy.

23. Goldberg, D. E.; Genetic Algorithms in Search, Optimization and Machine Learning, Addison-Wesley: Indianapolis, 1989.

24. Tropsha, A.; Gramatica, P.; Gombar, V. K.; QSAR Comb. Sci. 2003, 22, 69.

25. Randic, M.; J. Chem. Inf. Compt. Sci. 2004, 41, 607.

26. Todeschin, R.; Consonni, V.; Mauri, A.; Pavan, M.; Anal. Chim. Acta 2004, 515, 199.

27. ToMoCo-The Total System for Molecular Designs by the Computer Aided Chemisty Laboratory Version. 1.3, ChemInfonavi: Japan.

28. Cramer III, R. D.; Patterson, D. E.; Bunce, J. D.; J. Am. Chem. Soc. 1988, 110, 5959.

29. Williams S. P.; Sigler, P. B.; Nature 1998, 393, 392.

Received: April 16, 2009

Web Release Date: February 11, 2010

FAPESP helped in meeting the publication costs of this article. 